\title{
Idealismo y fundamentación
}

\author{
Aldo Guarneros Monterrubio
}

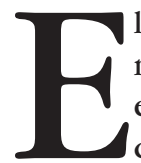

1 idealismo es uno de los "movimientos"1 más sobresalientes de la modernidad por el alcance ontológico de sus investigaciones. Surge, en cierto sentido, a partir de lo que llamamos racionalismo. Asimismo, como origen histórico del idealismo se suele traer a cuento el nombre de Platón. Sin embargo, dicho origen parece hacer del idealismo, a causa de una específica lectura de los diálogos platónicos, un tipo de reflexión que

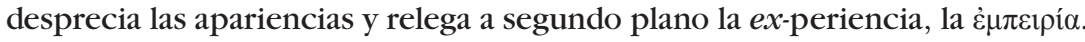
Se asume, así, que el único objetivo del idealismo es dirigirse al pensamiento humano, sin auxilio de algo ajeno. Su finalidad, según esto, sería establecer, desde ahí y en sí mismo, los conceptos que dan razón del mundo. La escisión es, pues, lo que suele sobresalir al hablar de idealismo. De acuerdo con este prejuicio, por una parte, están las ideas, cuya autonomía las sitúa en "otra realidad" y, por otra, está el mundo material, concreto, sensible o empírico que queda puesto entre paréntesis.

Las críticas hechas al idealismo a partir del siglo XIX y hasta nuestros días se basan en las distinciones analíticas de los filósofos modernos, las cuales conforman dualismos. Como primero de dichos dualismos, tanto en orden de importancia como desde una perspectiva genealógica de los problemas, se halla la distinción sujeto-objeto. Que el yo sea reducido al entendimiento, al alma, a la razón, al intelecto, al espíritu, al pensar o al percibir constituye el fondo de la aparente imposibilidad de diluir el límite entre el hombre y el mundo. Sin semejante disolución no se muestra la unidad y perfección del todo.

De este modo, la indagación acerca de las ideas, en tanto "materia" de examen del sujeto, se comprende generalmente como una investigación pre-

${ }^{1}$ Hago uso de las comillas porque la pluralidad de pensamientos que pueden caracterizarse como idealismo en la modernidad no serán tratados, en este ensayo, necesariamente como una escuela, sino en un sentido amplio como indagaciones de vario linaje en torno al significado de las ideas. 
eminente y previa al esclarecimiento de lo ex-sistente. Esto implicaría que lo posterior y secundario es aquello que no tiene el modo de ser de las ideas: la naturaleza, el cuerpo, lo extenso, lo palpable. Por esta razón, se asume que eso que es "secundario" queda en un plano diferente, ya sea porque se deja de lado, ya sea porque se pregunta por ello como un derivado de los conceptos e ideas comprendidas por el sujeto.

Puesto que las ideas se toman como edificaciones subjetivas, comúnmente la crítica consiste en señalar que esas concepciones no tienen asidero concreto ni real. La verdad, por lo mismo, adquiere un sentido científico-positivista, matemático o sólo explicable a partir de la comprensión del sujeto. ${ }^{2}$ Del mismo modo, el principio de unidad se considera fundamento sólo desde un ente específico (el hombre) o se asume como condición de posibilidad establecida fuera o "más allá" de la experiencia. Así, las ideas -y la verdad que reside en ellas- se consideran como un producto allende lo inmediato. En este sentido, decía irónicamente Albert Camus: "Se llaman verdades primeras a aquellas que descubrimos después de las demás, eso es todo". ${ }^{3}$

Sabemos de sobra cuán miopes suelen ser los encajonamientos en filosofía. Los "-ismos" de los que nos servimos para caracterizar las meditaciones de algunos pensadores (tales como racionalismo, empirismo, materialismo, existencialismo, nominalismo, realismo, etcétera) no aportan mayor comprensión al pensamiento de cada autor que es así calificado. Por el contrario, la delimitación de un pensamiento, a partir de estas categorías, entorpece la dilucidación de lo que fue meditado y cómo fue desarrollada la reflexión. Sin embargo, el idealismo - nombre del que conscientemente se sirvieron varios filósofos para calificar su propio sistema- parece ser una de las denominaciones más prejuzgadas y, por lo mismo, vale la pena esclarecer su sentido.

Esta exposición la llevo a cabo en tres partes. En la primera desarrollo el significado vulgar de idea, sobre el cual se fundamentan algunas críticas. Asimismo, expongo el origen específico del idealismo y el sentido más concreto que la idea adquiere entre los modernos. En la segunda parte reparo, con base

${ }^{2}$ Es conocida la crítica de Heidegger al sentido de verdad como certeza en la modernidad. Son diversos los escritos en los que la desarrolla. Uno de los más sobresalientes es el ensayo titulado La época de la imagen del mundo. En dicho texto elabora con bastante precisión la relación entre conceptos como representación, mundo, verdad-certeza, sujeto, ciencia y matemática. No obstante, cabe señalar que esa crítica permea dos de las obras de Heidegger que muestran la evolución de su reflexión y son tanto resultado como origen de otras obras, a saber, Ser y tiempo y Aportes a la filosofía. El primero de ellos aborda la crítica a partir del análisis del concepto de mundo y la fenomenología en el sentido de analítica existenciaria; el segundo la aborda desde el punto de vista del desarrollo histórico que parte del origen de la filosofía y se encamina a mostrar aquello que le subyace y es su condición de posibilidad.

${ }^{3}$ Albert Camus, La caída. Trad. de Manuel de Lope. Madrid, Alianza, 2007, p. 74. 
en la comprensión del idealismo, en aquello que logran fundamentar las ideas y cómo lo hacen. Finalmente, procurando mostrar qué podemos retomar de este proceder, llego a una reflexión sobre el alcance histórico del idealismo.

\section{Génesis de la investigación en torno a las ideas y su crítica inmediata. El sentido del idealismo en la modernidad}

Debido al sentido peyorativo del idealismo -que se establece a partir de una comprensión vulgar de la idea- la fundamentación del principio de unidad que los idealistas llevaron a cabo parece adquirir un carácter ajeno a lo existente y deviene plenamente subjetivo. Sin embargo, semejante consideración no atiende al sentido original de la idea, ni a su relevancia para el ser humano.

El concepto griego $1 \delta \varepsilon ́ \alpha$ se refiere primariamente a la apariencia. De acuerdo con esto, lo visible para los "ojos del alma" no es ajeno a lo que presentan los sentidos. Antes al contrario, aquello que se conoce a partir de la experiencia es también lo que, con una mirada depurada, se conoce en sí mismo.

La exigencia metódica entre los griegos no implicaba el abandono de toda sensación. Su énfasis radicaba, más bien, en que se atendiese adecuadamente a lo manifiesto. El recorrido filosófico lo comprendían como un adentrarse en lo que es. Esto es bastante claro en Aristóteles, gracias a su distinción entre lo primero por naturaleza y lo primero para nosotros. ${ }^{4}$ Pero igualmente Platón sostuvo ese recorrido desde lo aparente hasta lo que el ente es en sí. En los diálogos de transición y madurez es eminente el esclarecimiento de la dialéctica mediante la reminiscencia que parte no sólo de las ideas en sí mismas, sino que tiene su fundamento y alcance a partir de los que se percibe en la naturaleza..$^{5}$ Lo que muestran los entes es lo que permite comprender

\footnotetext{
${ }^{4}$ Pueden revisarse las distintas formulaciones con que expresa esto Aristóteles en las siguientes obras. De la Metafísica (trad. de Valentín García Yebra. Madrid, Gredos, 2012), pueden consultarse los siguientes pasajes, el primero de los cuales hace énfasis en el abrirse paso en el ente a partir de éste mismo: I, 3, 984a 18-19; v, 1, 1013a 1-3; VII, 4, 1029b 1-10. En el tratado Acerca del alma (trad. de Tomás Calvo Martínez. Madrid, Gredos, 2003) repite la formulación de la obra anterior: II, 2, 413 11-12. En la Ética nicomáquea (trad. de Julio Pallí Bonet. Madrid, Gredos, 2000) encontramos dos formulaciones distintas: III, 3, 1112b 23; I, 4, 1095b 2-3. Finalmente en los Analíticos segundos (trad. de Miguel Candel Sanmartín. Madrid, Gredos, 1995), hay una extensa explicación sobre la necesidad de que lo primero por naturaleza sea incluso condición de posibilidad de lo primero para nosotros, aun cuando metódicamente se llega a intuir lo más cognoscible por medio de lo menos cognoscible: I, 2, 71b 20-30.

${ }^{5}$ Notamos en las siguientes obras la constante referencia a la comprensión de la naturaleza y lo sensible como primer momento -indispensable además- de la dialéctica. En el Menón (trad. de F. J. Olivieri. Madrid, Gredos, 2004) la alusión a la unidad de la
} 
su fundamento como algo común a todos. Las sensaciones se complementan con las ideas. Por lo mismo, el mal-llamado idealismo de Platón -como sucede con otros pensadores griegos- no se trata de un rechazo a lo que se capta mediante los sentidos. El hincapié reside, más bien, en ejercitar la razón para que aquello que por sí mismo se presenta, tal como es, no sea empañado con una percepción errónea del alma. ${ }^{6}$

Así, pues, lo que sólo anacrónicamente puede llamarse idealismo antes de la modernidad es una afirmación de que en lo patente también se muestra algo a la razón que permite una mejor comprensión del principio. Lo que la "simple" experiencia pone de manifiesto es un modo de ser que no es palpable y que, no obstante, tiene igualmente realidad efectiva. Nuestra experiencia incluye, pues, la evidencia de la razón ( $\lambda$ ó ${ }^{\circ} \varsigma$ ), la intuición (voṽ, intuitus) y el entendimiento (intellectus), de tal suerte que es necesario comprender el carácter de estas capacidades que se ofrecen como contraparte y complemento de la materia. Santo Tomás expresó bellamente esta necesidad con las siguientes palabras: "[...] para que el universo sea perfecto, es necesario que exista alguna criatura incorpórea”. ${ }^{7}$

Lo incorpóreo, que otrora se identificó principalmente con Dios, viene a ser en la modernidad lo que eminentemente se comprende como la idea. La contemplación o teoría que permite comprender la verdad del todo es, entonces, una reflexión fundamentada en las ideas. En la modernidad se busca comprender este fundamento en sí a partir del saber humano. De ahí que, si bien las ideas no siempre se asumen como una simple construcción del alma, el análisis de las facultades del espíritu hace de las ideas un "material" primario del conocimiento.

Habiéndose comprendido las ideas como contenido exclusivo del entendimiento del hombre, se derivan otros dualismos, a saber, lo interno del espíritu y lo externo de la naturaleza, lo ideal y lo material, lo inteligible y lo sensible,

naturaleza: 81b-d. En el Fedón (trad. de Carlos García Gual. Madrid, Gredos, 2004) está la importancia de reconocer las ideas por la semejanza que surge de lo sensible: $75 \mathrm{a}-76 \mathrm{a}$. En el Banquete (trad. de M. Martínez Hernández. Madrid, Gredos, 2004) la aproximación desde la belleza presente en el cuerpo individual a la belleza que se concibe mediante el alma: 210a-211d. En la República (trad. de Conrado Eggers Lan. Madrid, Gredos, 2003) la "ascensión" desde la sombra de la opinión hasta la claridad del bien y el regreso desde esta forma intuida hacia aquello que fundamenta: vI, 510a-511c. Por último, en el Fedro (trad. de E. Lledó Íñigo. Madrid, Gredos, 2004) el anhelo del enamorado por la verdad y la doble técnica de la dialéctica: 249b-e, 265d-266e.

${ }^{6}$ En los fragmentos B107 de Heráclito y B7, vv. 3-5 de Parménides se advierte claramente la coincidencia de ambos pensadores. Su preocupación radica en la falibilidad propia de los sentidos. Mas el error no se debe a una imperfección de los sentidos en sí, sino al hecho de que se capte sin reflexión lo que estos muestran, al no haber preparación previa.

${ }^{7}$ Santo Tomás, Suma teológica II. Trad. de Raimundo Suárez, Jesús Valbuena y Alberto Colunga. Madrid, BAC, 2010, I, q. 50, a. 1. 
lo teórico y lo práctico, lo celeste y lo terrenal, lo nouménico y lo fenoménico, el alma y el cuerpo, la libertad y la mecánica, lo permanente y lo cambiante, el ser y el tiempo. Las críticas inmediatamente posteriores al idealismo, por lo tanto, consisten en problematizar aquel carácter antitético entre las ideas y lo otro. Al respecto podemos observar, por ejemplo, las críticas de Marx y Nietzsche al idealismo y a la metafísica que esa filosofía sostuvo.

Para Marx, la historia -comprendida a partir de la transformación social y económica, gracias a los distintos medios de producción- influye determinantemente en el desarrollo de la filosofía, puesto que da paso a cierto tipo de ideas que adquieren mayor influencia que otras. Así, escribe en su Manifiesto del Partido Comunista: “¿Qué otra cosa demuestra la historia de las ideas si no que la producción intelectual cambia de forma con la material? Las ideas dominantes de una época nunca han sido otra cosa que las de la clase dominante". ${ }^{8}$ De acuerdo con esto las ideas que produce el ser humano en su devenir intelectual no comprenden ningún tipo de autonomía respecto del proceso material. Las ideas no fundamentan la historia, sino que son consecuencia de otra "mutación". Pensar el mundo - como dice la conocida sentenciano implica una transformación. En la segunda de sus tesis sobre Feuerbach, Marx critica, por lo tanto, la noción de una aproximación a la verdad desde la mera contemplación de los fenómenos: "La pregunta sobre si el pensamiento humano se acerca a la verdad objetiva no es una pregunta de teoría, sino una pregunta de práctica. En la praxis debe demostrar el hombre la verdad, esto es, la realidad y fuerza, el carácter concreto de su pensamiento". 9 Las ideas, de esta forma, tienen un carácter diluido; sólo la acción pragmática logra un cambio y, así, la verdad adquiere sentido en su demostrabilidad.

Nietzsche, por su parte, también lleva a cabo una crítica a una larga tradición que culmina con el idealismo alemán por el carácter meta-físico del pensamiento, al cual denomina, por ello, tras-mundano. A causa del empecinamiento de la tradición en comprender la verdad y el fundamento a partir de lo que no deviene ni se percibe, Nietzsche señala la escisión que crea el hombre entre lo aparente y lo que se concibe "detrás" de ello. En semejante mundo -allende lo aparente- el mayor contrasentido radica en no hallar el fundamento buscado, pues la tradición misma lo ha agotado y aquello que queda como rezago -lo único que puede lograr que el fundamento interpelesería, en todo caso, el hombre mismo que se empecina en la razón. En Así habló Zaratustra escribe lo siguiente:

${ }^{8}$ Karl Marx, Manifiesto del Partido Comunista. Trad. de Pedro Ribas. Madrid, Alianza, 2005, p. 66.

${ }^{9}$ Georges Labica, Karl Marx: Thesen über Feuerbach. Hamburgo/Berlín, Argument, 1998, p. 12. La traducción es mía. 
Fatiga, que de un solo salto quiere llegar al final, de un salto mortal, una pobre fatiga ignorante, que ya no quiere ni querer: ella fue la que creó todos los dioses y todos los trasmundanos [...] Pero "aquel mundo" está bien oculto a los ojos del hombre, aquel inhumano mundo deshumanizado, que es una nada celeste; y el vientre del ser no habla en modo alguno al hombre, a no ser en forma de hombre. ${ }^{10}$

Con la figura del salto, Nietzsche ironiza la confianza con la que Platón y Aristóteles dan razón del principio. La esperanza que sostienen estos griegos -la cual se mantiene frente a la ceguera que amenaza al alma (Platón) y el regreso al infinito que no logra explicar las causas (Aristóteles)- es comprendida por Nietzsche como fatiga, agotamiento, acrecentamiento del desierto.

Dos de las grandes críticas a la metafísica en general y al idealismo en particular consisten, entonces, en la falta de concreción de las ideas o su esterilidad a causa de su impotencia efectiva.

Ahora bien, estas críticas parten de la noción de idea como un modo de pensar que, por su especificidad, no se identifica en absoluto con la realidad de lo ex-sistente, es decir, parece no corresponder con lo que está "fuera" de la mente y puesto delante: el ob-jectum. Si las ideas no guardan esa relación, pueden darse dos problemas principales: ya sea que la consecuencia consista en que la idea no tiene, por lo tanto, más que un carácter subjetivo y carente de veracidad, ya sea que la idea pretenda portar en sí toda certeza y, por lo mismo, se deje sin examinar aquello que tiene un carácter ajeno. En cualquiera de ambos casos el fundamento ideal establecería una dicotomía y, por lo tanto, no sería propiamente ni fundamento ni principio. Sin embargo, el sentido de la idea no ha sido asumido de manera uniforme en la modernidad.

Uno de los primeros idealistas -haciendo un uso más propio del conceptoes George Berkeley. A diferencia de Platón, los neoplatónicos y otros griegos en los que la idea -o forma-denotaba el aspecto del ente que constituía su propia naturaleza y que, sólo por ello, era comprensible para el alma, con Berkeley el conocimiento reside en las ideas que tienen lugar únicamente desde la percepción del sujeto. Por lo tanto, Berkeley determina una diferencia a partir de la sensación y no a partir del modo en que el objeto que se investiga es captado. En otras palabras, comprende la materia como sustancia no percipiente y, por lo tanto, ajena a las ideas que fundamentan la realidad. Escribe en su Tratado: "Por materia debemos entender una sustancia inerte e insensible en la que subsisten realmente la extensión, la figura y el movimiento. Pero es evidente [...] que la extensión, la figura y el movimiento son sólo

${ }^{10}$ Friedrich Nietzsche, Así habló Zaratustra. Trad. de Andrés Sánchez Pascual. Madrid, Alianza, 2005, p. 61. 
ideas que existen en la mente [...]"11 Con esta afirmación, no obstante, aquella empresa que señaló Santo Tomás -siguiendo a la tradición-, de comprender la perfección del todo desde sus diversos ámbitos, queda reducida a uno solo de ellos: el incorpóreo. Así, Berkeley ni siquiera da paso a un dualismo, sino a una suerte de absolutismo escindido, lo cual es, evidentemente, un contrasentido.

A partir de este filósofo comprendió Kant las consecuencias del idealismo y propuso su crítica de la razón como idealismo trascendental:

El idealismo -dice Kant refiriéndose a Berkeley- consiste en la afirmación de que sólo hay seres pensantes; las otras cosas que creemos percibir en la intuición serían solamente representaciones en los seres pensantes, a las cuales en verdad no les correspondería ningún objeto que se encontrase fuera de estos. Yo, al contrario, digo: las cosas nos son dadas como objetos de nuestros sentidos, objetos situados fuera de nosotros; pero de lo que puedan ser en sí mismas nada sabemos, sino que conocemos solamente sus fenómenos, esto es, las representaciones que producen en nosotros al afectar nuestros sentidos. ${ }^{12}$

Las consecuencias de la postura adoptada por Kant hacen de las ideas todo lo opuesto a lo que significaban para Berkeley. Para Kant son sofisterías e ilusiones que la razón pura conforma. Su genealogía se da a partir del escaso campo de conocimiento verdadero que la filosofía trascendental admite de acuerdo con los "elementos" que aportan la intuición y el entendimiento a la síntesis de la imaginación. Lo que es -lo externo- no tiene su correlato en las ideas -lo interno. A lo más cabría afirmar que las ideas son un intento por aproximarse a aquello que no se puede aprehender mediante el espacio o el tiempo, ni mediante las categorías. Mas la adecuación nunca se logra.

Lo externo y lo interno, que introduce Kant al hablar de la cosa en sí del objeto y del fenómeno que se adquiere mediante la sensibilidad, afirman un dualismo irreductible. Él mismo, incluso, admite sin recelo dicha escisión: “[...] el idealista trascendental puede ser un realista empírico y, por lo tanto [...] un dualista; es decir, que puede admitir la existencia de la materia sin salir de la mera conciencia de sí mismo, y sin suponer nada más que la certeza de las representaciones en mí". ${ }^{13}$ Kant se posiciona, así, en medio de la pugna de dos posturas: por una parte, la aceptación de la existencia independiente de la

${ }^{11}$ George Berkeley, Tratado sobre los principios del conocimiento humano. Trad. de Concha Cogolludo Mansilla. Madrid, Gredos, 2003, I, \& 9, p. 57.

${ }^{12}$ Immanuel Kant, Prolegómenos a toda metafísica futura que haya de poder presentarse como ciencia. Trad. de Mario Caimi. Madrid, Istmo, 1999, $₫ 13$, Ak 188-189.

${ }^{13}$ I. Kant, Crítica de la razón pura. Trad. de Mario Caimi. México, FCE/UAM/UnAM, 2009, A 370. 
materia -a lo que denomina idealismo empírico- ${ }^{14} \mathrm{y}$, por otra, la negación, ya sea absoluta, ya parcial, de la subsistencia de la materia independientemente del sujeto -que llama idealismo dogmático y escéptico, respectivamente. ${ }^{15}$

La postura kantiana, en este sentido, evita el arduo camino que consiste en demostrar -o reconocer la imposibilidad de demostrar- la existencia de la materia, así como elude la comprobación sobre qué tanto se adecua la idea a aquello que subsiste por sí mismo. Así, pues, la postura dogmática es la que sostiene Berkeley y la trascendental, evidentemente, la que defiende Kant. Líneas después veremos la virtud que esta postura trascendental aporta a la investigación del principio. Sin embargo, antes cabe decir algo más sobre el idealismo en ciernes a comienzos de la modernidad.

Al hablar de dogmatismo, Kant suele hacer referencia a los racionalistas, es decir, al desarrollo de aquella metafísica, próxima a él, que acepta la subsistencia del ente como objeto en sí cognoscible por el sujeto. No obstante, en lo que concierne al idealismo, el dogmático es, más bien, aquel que no admite dicha autonomía del ser y de la verdad en las cosas. Por lo tanto, teniendo el idealismo empírico una actitud contraria al idealismo dogmático, cabe considerar que, pese a la moderación - muchas veces inadvertida- de parte de Descartes, Spinoza y Leibniz, es a estos pensadores a los que Kant considera representantes del idealismo empírico. Por lo demás, resulta evidente la preeminencia de Descartes en los impulsos de las variadas indagaciones sobre el origen de las ideas, así como las operaciones que a éstas les corresponden y sus alcances.

Los únicos caminos de investigación que distingue Descartes, en las $R e$ glas para la dirección del espíritu, que le sirven a lo largo de su obra para expresar el principio de la filosofía y para desarrollar el criterio de verdad en tanto claridad y distinción, son "[...] la experiencia o la deducción". ${ }^{16} \mathrm{La}$ noción de experientiam parece entrañar aquí un contrasentido, de acuerdo con la cómoda -y sumamente inadecuada- distinción entre racionalismo y empirismo. ${ }^{17}$ Todavía más llamativo resulta dicho concepto, puesto que mienta lo que en otros pasajes denomina Descartes intuición y, en las Meditaciones, percepción. Experiencia, intuición y percepción nombran un conocimiento inmediato del principio absoluto, del cual parte la deducción para desarrollar la mathesis universal. En la octava regla afirma Descartes, además, que el inexperto es quien no comprende que el entendimiento es lo primero que se

${ }^{14}$ Cf. ibid., A 369.

${ }^{15}$ Cf. ibid., A 377.

${ }^{16}$ René Descartes, Reglas para la dirección del espíritu. Trad. de Juan Manuel Navarro Cordón. Madrid, Alianza, 2003, regla II, p. 73.

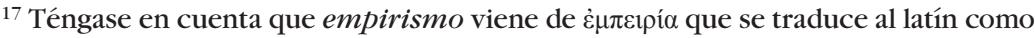
experientia. 
ha de conocer y aquello a partir de lo cual se derivan las demás facultades del alma, del mismo modo que ignora que el examen del entendimiento permite descubrir lo verdadero y lo falso, es decir, todo aquello en lo que puede ahondar el pensamiento sin cometer errores. ${ }^{18}$

La denominación kantiana de idealismo empírico (experiencial), por lo tanto, no es del todo inadecuada. Sin embargo, lo fundamental del análisis cartesiano de las ideas no radica en la asunción, sin más, de la realidad objetiva del ente externo al sujeto, sino en que son las ideas mismas las que pueden portar la objetividad. De este modo, en Descartes se identifican el fundamento del ser y del conocer, a diferencia de lo que sucede con Berkeley y Kant.

No pretendo desarrollar los tres tipos de ideas que distingue Descartes ni el origen de cada una de ellas. De momento me resulta más significativa la compleja distinción que lleva a cabo entre los "grados" de realidad de las ideas en la tercera de sus Meditaciones. Para desenrollar el nudo gordiano del solipsismo, Descartes afirma la tesis de que la realidad que portan los entes también corresponde a las ideas que de ellos tenemos: "Una cosa está objetivamente en el entendimiento por su idea [...]"19 Si la objetividad puede hallarse en el entendimiento, la realidad de la idea no consiste sólo en ser una operación mental, sino que le viene de aquello de donde proviene la idea. Así, pues, previa a la diferenciación entre ideas innatas, adventicias y creadas, está la distinción entre ideas mayor o menormente perfectas.

Desde el prefacio al lector, Descartes advertía esa ambivalencia del concepto de idea: "Hay un equívoco en idea, pues puede entenderse, o bien materialmente, como operación del entendimiento, y en tal sentido no puede decirse que sea más perfecta que yo, o bien objetivamente, como la cosa representada por esa operación [...]"20 Posteriormente en sus Meditaciones -igual que hizo con las nociones de experiencia e intuición en las Reglas-Descartes hace una sustitución del concepto de idea en sentido material, para hablar de idea en sentido formal o actual. De esa manera, Descartes añade la siguiente distinción: "El modo objetivo de ser corresponde por naturaleza a las ideas [...] el modo formal de ser corresponde por naturaleza a las causas de las ideas, por lo menos a las primeras y principales". ${ }^{21}$ Objetivamente, entonces, las ideas no conforman la totalidad de la realidad, ni deponen su sentido y concreción ante la independencia incondicionada de la materia, sino que adquieren un vínculo con el ente gracias a que formalmente esas ideas tienen su fundamento en la intuición o percepción, cuya causa es Dios.

${ }^{18}$ Cf. ibid., p. 111.

${ }^{19}$ R. Descartes, Meditaciones metafísicas y otros textos. Trad. de E. López y M. Graña. Madrid, Gredos, 2003, p. 38.

${ }^{20}$ Ibid., p. 12.

${ }^{21}$ Ibid., p. 38. 
Si comprendemos la génesis del idealismo desde las tesis cartesianas, lo que el idealismo desarrolla no es una simple doctrina del condicionamiento subjetivo de la verdad a partir de pensamientos construidos sin contenido concreto. Por el contrario, se trata de una aprehensión de la realidad en sus fundamentos, a partir del modo adecuado que tiene el hombre para percibir el principio de unidad. Lo que la idea logra es llegar a aquella razón común que sintetiza (reúne) y analiza (suelta, desenreda) todo conocimiento y toda existencia.

Fue con esa misma idea que Spinoza habla en su Ética del tercer género de conocimiento, el más perfecto, denominándolo ciencia intuitiva. Este género se trata del conocimiento que parte de lo primero o del principio, es decir, de las ideas que pueden comprender lo simple y absoluto, para llegar paulatinamente a todo otro saber particular que necesariamente está emparentado: "[...] este género de conocimiento progresa a partir de la idea adecuada de la esencia formal de ciertos atributos de Dios, hacia el conocimiento adecuado de la esencia de las cosas". ${ }^{22}$ El idealismo tiene, pues, el objetivo de esclarecer la correspondencia entre la cohesión de los entes en su existir y la coherencia de la ciencia en el conocer. Lo que está a la base es la unidad del todo. La afirmación de esta unidad, para Spinoza, está de sobra, al ser sumamente clara y distinta: "[...] la unidad ni se distingue en modo alguno del ser ni le añade nada, sino que sólo es un modo de pensar, con el que separamos una cosa de las demás, que son semejantes a ella o que concuerdan de alguna forma con ella". ${ }^{23}$ En tanto modo de pensar la unidad no altera sustancialmente al todo que es unitario por naturaleza, por lo tanto, no requiere reiteración. No obstante, a pesar de lo que señala Spinoza, en la interrelación de lo uno y lo múltiple -y su explicitación- está una de las claves del idealismo.

Así, el auténtico sentido del idealismo para Hegel -que comprendió la concreción de las ideas y el historicismo de la filosofía- se asentaba en la interrelación entre la unidad y la pluralidad de la realidad en su desarrollo, que implica creatividad y acrecentamiento, así como en el pensamiento e intuición de esta realidad, que no es ni parcial ni unilateral:

El idealismo de la filosofía no consiste en nada más que en esto: no reconocer lo finito como un verdadero existente. Cada filosofía es esencialmente un idealismo, o por lo menos lo tiene como su principio, y el problema entonces consiste sólo en reconocer en qué medida ese

${ }^{22}$ Baruch Spinoza, Ética demostrada según el orden geométrico. Trad. de Vidal Peña. Madrid, Alianza, 2006, II, proposición LX, escolio II, p. 164.

${ }^{23}$ B. Spinoza, Pensamientos metafísicos. Trad. de Atilano Domínguez. Madrid, Alianza, 2006, I, vI, p. 257. 
principio se halla efectivamente realizado [...] Una filosofía que atribuye a la existencia finita en cuanto tal un ser verdadero, último y absoluto, no merece el nombre de filosofía; [...] lo ideal [...] se trata sólo de un único todo concreto, del cual son inseparables los momentos. ${ }^{24}$

Viendo al idealismo no sólo como una "doctrina" particular, sino como constituyente del carácter filosófico, su virtud consiste en poseer la apertura de las ideas que permite expresar el principio de unidad -aunque no sea de manera cabal-, el cual, de otro modo, estaría ceñido a la unilateralidad de la simple materia o lo meramente sensible y, por tanto, sería muy limitado. Razón de sobra tenía Hegel para extrañarse de que la verdad siempre quisiese verse como algo palpable, casi espacial, pues la verdad no se agota sólo en esto. Desde luego, tampoco sucede que la verdad trascienda el mundo en un más allá. La verdad trasciende, más bien, en una inmanencia que da luz sobre la perfección del todo, de lo completo.

Al dotar de un nuevo significado al idealismo, Hegel buscó deshacerse de los prejuicios que pesaban sobre las nociones de idea y pensamiento en tanto modalidades exclusivas del ser humano. De esta manera, se aproximó al sentido griego de la idea entendido como aspecto -tanto el aspecto particular del ente como el común- a partir del cual el ente tiene su existencia y el principio puede llegar a intuirse. La idea, en opinión de Hegel, no es lo que los hombres tienen, sino lo que son. ${ }^{25} \mathrm{El}$ idealismo, es decir, la investigación en torno a las ideas, consiste en la comprensión de nuestro propio ser. Esta comprensión no se limita a desentrañar un aspecto del hombre, sino el aspecto general $(i \delta \varepsilon \dot{c} \alpha)$ que portamos en nuestro ser. Así, pues, la teoría del conocimiento $y$ otros "campos" de estudio filosófico no se establecen en sí mismos, sino que llevan a cabo, a la par, una decisión sobre el principio de unidad, el cual es, indefectiblemente, el objeto al que alude toda investigación filosófica.

\section{La fundamentación por parte del idealismo como re-conocimiento}

En su Fundamentación de la metafísica de las costumbres, Kant describió del siguiente modo la tarea del idealismo trascendental: "La presente fundamentación [...] no es nada más que la búsqueda y establecimiento del principio

\footnotetext{
${ }^{24}$ Georg Wilhelm Friedrich Hegel, Ciencia de la lógica I. Trad. de Augusta y Rodolfo Mondolfo. Buenos Aires, Solar/Hachette, 1993, pp. 197-198.

${ }^{25}$ Cf. G. W. F. Hegel, Enciclopedia de las ciencias filosóficas. Trad. de Ramón Valls Plana. Madrid, Alianza, 2005, § 482, p. 521.
} 
supremo [...], lo cual constituye por sí solo un quehacer aislado, entero en su propósito [...]"26 La fundamentación, podría creerse, no es más que la fijación o estatismo de la razón pura, lo cual se asienta firmemente en principios no evidentes (en el sentido de no fenoménicos). Pero la fundamentación de la moral, del placer o displacer y del conocimiento no tiene el sentido de una autodeterminación o auto-imposición de los principios. El conocimiento no es caprichoso, sino que se establece en relación con los principios presentes en lo que es, aunque no sean materia especulativa.

Llama la atención el concepto que utiliza Kant para referirse al conocimiento en general y, específicamente, al conocimiento por principios a priori, a saber, Erkenntnis. Este término puede traducirse simplemente como conocimiento, aunque quizá es más significativo traducirlo como comprensión. Comprehender significa la reunión de lo múltiple. De ahí que a la síntesis la denomine Kant, en la Crítica de la razón pura, el origen primero del conocimiento o fundamento de la unidad: "Entiendo por síntesis [...] la acción de añadir unas a otras diversas representaciones, y de comprender su multiplicidad en un conocimiento; [la síntesis] es aquello que propiamente recolecta los elementos [...] y los reúne en cierto contenido [...]"27

Además de este significado del sustantivo Erkenntnis, el verbo alemán erkennen puede traducirse como re-conocer. Así, el idealismo absoluto de Hegel hacía una diferencia entre das bekannt-lo consabido o aquello que es conocido a medias-y das erkannt-lo re-conocido. De acuerdo con Hegel, el problema que presenta el entendimiento vulgar para dar razón del todo consistía en que lo conocido en general, justo porque se da por consabido, no es reconocido. ${ }^{28} \mathrm{La}$ dificultad viene, entonces, al no estar atentos a lo común, como señaló Heráclito. El quehacer de la filosofía no es llegar, al final de la investigación, al descubrimiento de la verdad o del principio de unidad, sino reconocer su comunidad original. Por lo tanto, el idealismo no lleva a cabo una creación ex nihilo de los principios. El dar razón no quiere decir donar o imponer fundamentos a partir del hombre como ente aislado, sino comprender lo dado al hombre por aquello que investiga. El máximo esfuerzo de la fundamentación consiste en reconocer aquello que ya siempre se conoce, esto es, lo común.

${ }^{26}$ I. Kant, Fundamentación de la metafísica de las costumbres. Trad. de José Mardomingo. Barcelona, Ariel, 1999, Ak 392. El subrayado es mío.

${ }^{27}$ I. Kant, Crítica de la razón pura, B 103.

${ }^{28}$ Cf. G. W. F. Hegel, Phänomenologie des Geistes. Fráncfort del Meno, Suhrkamp, 1986, p. 35. La traducción es mía. En alemán dice: "Das Bekannte überhaupt ist darum, weil es bekannt ist, nicht erkannt". Cf. también Wissenschaft der Logik I. Fráncfort del Meno, Suhrkamp, 1986, p. 22. 
Este trabajo, que bien puede considerarse inútil y fácil es, justamente por su "sencillez", de lo más complicado. Basta tener en cuenta, como ejemplo de esto, con cuánta reserva hablamos actualmente del fundamento común, del principio de unidad y de la verdad, del mismo modo que observamos con qué facilidad nos dispensamos de llevar a cabo esta fundamentación. En el denominado "progreso" histórico de los quehaceres humanos, entre los que se cuenta a la filosofía, se siguen cada vez más los discursos parciales. Se reniega de lo común (como si lo particular no conformase también el todo). La comodidad de la fragmentación del pensamiento y la disposición de la interpretación hacen de la comprensión algo extraviado. Se considera salvaguardada la filosofía siempre y cuando se limite a modelos metodológicos ajenos. Finalmente, su utilidad se comprende sólo si se encuentran "a la moda" tanto su objeto de investigación como su desarrollo histórico.

Sin embargo, estas tendencias parcializantes sólo pueden darse a partir del fundamento común y gracias a la posibilidad creativa que éste permite. Dicho

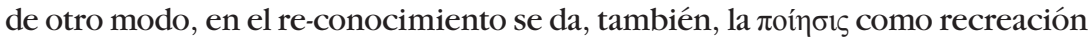
histórica. La fundamentación es, pues, renovación de lo mismo. Únicamente sobre la base de esta recreación unificadora pueden existir corrientes negativas. La historia no consiste en un asentamiento inamovible de doctrinas, sino en el acrecentamiento del fundamento y la verdad. Esto fue lo que advirtió Hegel en la Fenomenología del espíritu: "[...] la sustancia es lo en-sí todavía sin desarrollar, o el fundamento y concepto dentro de su simplicidad [...] El conocer (das Erkennen) [...] es la conciencia espiritual, a cuyos ojos lo que es en sí sólo es en la medida en que es ser para el sí-mismo y ser del sí-mismo o concepto [...]" 29 Es necesario comprender que, con estas palabras, Hegel no sostiene el dominio del sujeto - entendido como el hombre- sobre la sustancia, sino la afirmación de la unidad de la filosofía como reconocimiento histórico del propio fundamento sobre sí mismo.

Esto quiere decir, por una parte, que el objeto de investigación, en tanto es común, es de por sí fundamento y su ser constituye la verdad en su auto-conformación. Por otra parte, implica que ninguna reflexión y ninguna actividad pueden desarrollarse sin fundamento. Éste no puede desdeñarse porque no es problemático por sí, es decir, no depende de construcciones teórico-científicas que pueden ser malogradas, como sucede con las leyes y postulados axiomáticos. Al contrario, el problema consiste en el modo de concebir y percibir el fundamento. Así, por ejemplo, Nicol mostraba en Los principios de la ciencia la diferencia entre fundamento y principio, por una parte, y axioma, por otra parte, pues los axiomas son hipótesis de una razón determinada y finita:

${ }^{29}$ G. W. F. Hegel, Fenomenología del espíritu. Trad. de Antonio Gómez Ramos. Madrid, Abada/UAM, 2010, p. 909. 
[...] los principios de la ciencia, entendidos como fundamentos [...] no los establece o crea la ciencia misma. A ella le son dados, porque en ella se funda la existencia humana, antes de que la ciencia nazca, y aparte de su discurso: son condiciones o formas del ser en general, no sólo del ser analizado científicamente; y del conocer en general, no sólo del que se organiza con método y sistema. ${ }^{30}$

En este sentido podríamos afirmar que no hay principios particulares, ni verdades parciales, ni "filosofías de..." que no sean, en rigor, partícipes de la fundamentación del todo. Cualquier indagación forma parte ya de lo común a todo pensamiento. Razón de sobra tenía Descartes para sentirse extrañado de la máxima atención que se le prestaba a los campos de investigación particulares, sin reparar en lo que articula y cohesiona cualquier ciencia:

[...] me parece asombroso que casi todo el mundo estudie a fondo y con toda atención las costumbres de los hombres, las propiedades de las plantas, los movimientos de los astros, las transformaciones de los metales y otros objetos de ciencias semejantes, mientras que casi nadie se ocupa del buen sentido o de esta sabiduría universal, cuando, sin embargo, todas las otras cosas deben ser apreciadas no tanto por sí mismas cuanto porque aportan algo a ésta [...] pues nada nos aleja más del recto camino de la búsqueda de la verdad que el dirigir los estudios no a este fin general, sino a algunos particulares. ${ }^{31}$

La autoconciencia surge en la modernidad como comprensión de la subjetividad. El idealismo la desarrolla concretamente y bajo diversas formas. Hay, efectivamente, diferencias entre esta autoconciencia y aquella que impregna la filosofía de los antiguos griegos. El significado de sí-mismo, es decir, el modo de considerar este fundamento del hombre es lo que permite esclarecer la diferencia histórica. Sin embargo, me resulta de mayor importancia hacer énfasis en lo común de estas épocas históricas, a saber, que en rigor ningún tipo de introspección puede ser absolutamente pura. La auto-gnosis no se logra sin lo que, análogamente, podríamos llamar allognosis: el conocimiento de lo otro. Mediante uno mismo se comprende el todo. Esta afirmación no es exclusiva de la filosofía griega; incluye toda la historia filosófica.

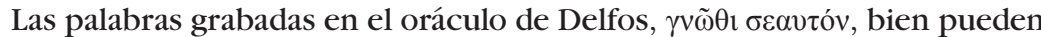
caracterizar los varios esfuerzos por dar razón en la historia. El sentido que

${ }^{30}$ Eduardo Nicol, Los principios de la ciencia. México, FCE, 2001, p. 425.

${ }^{31}$ R. Descartes, Reglas para la dirección del espiritu, regla I, pp. 65-67. El subrayado es mío. 
posee el verbo griego $\gamma \downarrow \gamma v \omega ́ \sigma \kappa \omega$ quiere decir un experimentar íntimo y carnal. Por lo tanto, se trata de una suerte de re-flexión. Así, pues, esa sentencia-que, según se dice, uno de los siete sabios grabó en el oráculo- podría traducirse incluso como reconócete a ti mismo. El conocimiento se fundamenta en el reconocimiento íntimo, en un adentrarse, que no es lo mismo que ir "más allá" de lo que es, sino un volver sobre sí mismo para que el pensamiento se vuelva, a su vez, con mayor atino sobre aquello que es manifiesto para los sentidos. No es gratuito que Hegel, en su Ciencia de la lógica, denominase al fundamento - así como al fenómeno- una determinación de la re-flexión, pues es una vuelta sobre sí desde la raíz que constituye al ente o, dicho de otro modo, es una comprensión más ejercitada.

El fundamento, como las otras determinaciones reflexivas, ha sido expresado en un principio: todo tiene su razón suficiente. Esto, en general, no significa otra cosa sino: lo que existe tiene que ser considerado no como un inmediato existente, sino como algo puesto. No hay que detenerse en general en el ser determinado inmediato o en la determinación en general, sino que hay que volver desde ellos a su fundamento. ${ }^{32}$

Con el principio de razón suficiente - al que hace referencia Hegel- Leibniz fundamentó tanto las verdades contingentes o de hecho, como las verdades necesarias o de razón. En esta fundamentación común de la verdad Leibniz elude la imposición de la razón particular del hombre, para dar paso al reconocimiento de la razón intrínseca a todo átomo sustancial. De ahí el concepto de apercepción. En Principios de la naturaleza y de la gracia fundados en la razón describe Leibniz del siguiente modo la operación de esta facultad del espíritu: "[...] es bueno distinguir entre la percepción, que es el estado interno de la mónada que representa las cosas externas, y la apercepción, que es la conciencia o conocimiento reflexivo de este estado interior [...]"33 Pese a que en estos términos parece haber una escisión entre dos estados ontológicos, uno interno y el otro externo, no es un dualismo lo que se fundamenta, sino la interrelación y unidad entre un conocimiento dado y su reconocimiento mediante la conciencia - con lo cual Kant y Hegel siguieron a Leibniz.

Es notable que, en otro escrito, Leibniz describiese el principio primero de su filosofía sin servirse primordialmente del principio de razón suficiente.

${ }^{32}$ G. W. F. Hegel, Ciencia de la lógica II. Trad. de Augusta y Rodolfo Mondolfo. Buenos Aires, Solar/Hachette, 1993, pp. 81-82.

${ }^{33}$ Gottfried Wilhelm Leibniz, "Principios de la naturaleza y de la gracia fundados en la razón”, en Escritos filosóficos. Trad. de Ezequiel de Olaso. Madrid, Antonio Machado Libros, 2003, §4, p. 682. 
Este otro principio consiste en mostrar la relación entre lo intrínseco y lo extrínseco. En una carta que escribe a Antoine Arnauld, fechada el 14 de julio de 1686, leemos lo siguiente:

[...] la noción de la sustancia individual encierra todos sus acontecimientos y todas sus denominaciones, incluso las que se llaman vulgarmente extrínsecas [...] puesto que es necesario que haya siempre algún fundamento de la conexión de los términos de una [posibilidad], ${ }^{34}$ el cual debe encontrarse en sus nociones. Este es mi gran principio, [...] uno de cuyos corolarios es el axioma vulgar de que sin razón nada hay $[\ldots]^{35}$

Lo que expresa el gran principio de Leibniz no es otra cosa más que la perfección armónica del todo. De esta simple idea surge el fundamento de la razón que permite mostrar la cohesión de aquello que existe, aunque se dé en diversos modos y a partir de distintos principios (como sucede con las causas eficientes y finales, es decir, el "mundo" mecánico y el espiritual).

Igualmente, Spinoza expresó este fundamento de la multiplicidad-de modos y atributos- en la unidad de la sustancia absoluta: "No puede una cosa ser causa de otra, si entre sí nada tienen en común". ${ }^{36}$ No habiendo para Spinoza más que una única naturaleza, es decir, Dios, no hay distintas sustancias sin interrelación, sino una causalidad necesaria que comprendemos por medio de la intuición, a partir de las ideas que se derivan de la esencia de los atributos.

Así, pues, si el principio de razón suficiente de Leibniz es un corolario de ese otro principio que podríamos entender como principio de comunidad, entonces, el fundamento que expresa la mónada es la síntesis -o relación- de percepciones y de ideas mediante las cuales todo átomo sustancial se desenvuelve y deviene en la existencia. En otras palabras, no se trata de un átomo aislado, sino del fundamento de la coherencia entre lo interno y lo externo, lo moral y lo mecánico, lo espiritual y lo físico, el movimiento eficiente y el perfeccionamiento final.

En este sentido valdría la pena aceptar que el idealismo lleva a cabo una fundamentación en tanto reconocimiento de lo que ya siempre se conoce -lo patente y manifiesto- y que se da como asentamiento de la unidad mediante la interiorización en uno mismo y en lo otro. Aquellos pensado-

${ }^{34}$ La traducción de Losada dice "una proposición", mientras que en la edición francesa se puede leer: "[...] puisqu'il faut qu'il y ait toujours quelque fondement de la connexion des termes d'une possibilité [...]"

${ }^{35}$ G. W. Leibniz, Correspondencia con Arnauld. Trad. de Vicente P. Quintero. Buenos Aires, Losada, 2004, p. 67. El subrayado es mío.

${ }^{36}$ B. Spinoza, Ética demostrada según el orden geométrico, I, proposición III, p. 49. 
res, que a lo largo de la modernidad han meditado sobre el sentido fundamental y unificador de la idea, han denominado este acto de reconocer de varios modos: yo pienso (Descartes), amor intelectual (Spinoza), conciencia de las representaciones (Leibniz), apercepción trascendental (Kant), rememoramiento espiritual (Hegel).

\section{Notas finales sobre el alcance del idealismo en la historia}

La autoconciencia y la introspección que exige el idealismo para comprender la unidad de toda modalidad del crear, hacer, padecer, intuir y conocer es el método que permite la comprensión de lo común - del principio de unidad-y que proyecta históricamente cualquier recreación. De esto ya era consciente Platón, quien preguntaba: “ ¿[...] es posible comprender adecuadamente la naturaleza del alma, si se la desgaja de la naturaleza en su totalidad?" 37 Es evidente que la respuesta es negativa, pues semejante escisión no es siquiera comprensible.

Al investigar lo que es en sí, el idealismo y la filosofía en general no se preguntan por lo escindido, sino por aquello que permite la interrelación. Estando toda la naturaleza emparentada, como decía Platón en el Menón, "una investigación parcializada vale tan poco como una opinión cualquiera. La verdad no es ajena al hombre". Al contrario, si hay algo así como un a priori, éste lo constituye la verdad, puesto que es aquello a partir de lo cual el hombre actúa y piensa. La introspección, antes que Hegel, la caracterizó Platón mediante un modo del reconocer que parte tanto de lo sensible, como de lo inteligible (ambos a la vez): "[...] nunca el alma que no haya visto la verdad puede tomar forma humana. Conviene que, en efecto, el hombre se dé cuenta de lo que le dicen las ideas, yendo de muchas sensaciones a aquello que se concentra en el pensamiento. Esto es, por cierto, la reminiscencia de lo que vio, en otro tiempo, nuestra alma [...]"38

En esto siguió Aristóteles a Platón. En la Metafísica, al caracterizar la filosofía en conformidad con las nociones de sabiduría y sabio, Aristóteles comprendió la filosofía como ciencia que estudia el todo y lo más difícil, es decir, como una ciencia que es capaz de enseñar, comprende de manera exacta, se busca por sí misma y ha de mandar. En otras palabras, la filosofía es la ciencia de lo universal, aquella que muestra cómo el todo se integra a sí mismo en su perfección. Pero todo esto no apunta a lo que está "más allá" de los fenómenos. Al contrario, dice posteriormente Aristóteles, "[...] la sabiduría busca la causa

${ }^{37}$ Platón, Fedro, 270c.

${ }^{38}$ Ibid., 249b-c. El subrayado es mío. 
de las cosas manifiestas [...]"39 No se busca lo oculto, lo supra-celeste, ni lo

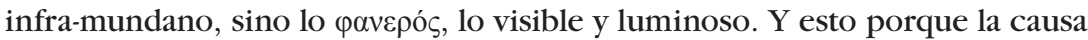
primera es aquella "[...] por la cual actúa todo entendimiento y toda naturaleza [...]" ${ }^{40}$ Es decir, es lo manifiesto en toda teoría y praxis.

Al describir los primeros pasos de la filosofía, Aristóteles señalaba que, "[...] al avanzar, la cosa misma les abrió el camino [a los hombres] y les obligó a investigar". ${ }^{41}$ Líneas después dice con mayor especificidad que los primeros filósofos investigaban "[...] obligados [...] por la verdad misma [...]"42 Esto significa que es la naturaleza, lo común, el principio o fundamento, lo que da los impulsos, lo que por sí mismo es el principio del deseo y de la tendencia al saber. La verdad es, pues, el élan vital de la filosofía, es decir, no un resultado, sino lo que impele desde el origen a seguir buscando el principio.

En este comportamiento trans-histórico de la verdad podemos dar razón de la fundamentación que lleva a cabo el idealismo. Dicho de otro modo, el idealismo puede ser entendido no sólo como un "movimiento" o "corriente filosófica" de una época determinada, sino como algo presente en distintos momentos. Con esta afirmación no busco establecer anacronismos, ni imponer una moda en el devenir del pensamiento filosófico subsecuente. Lo que pretendo es la comprensión de la unidad histórica en cuyo integramiento se muestra la verdad misma y aporta nuevas comprensiones a esta indagación común por el principio de unidad. Esto mismo es lo que han logrado los pensadores gracias a su diálogo con el pasado y a las posibilidades que abren para el porvenir.

En el siglo XX una de las "corrientes" más influyentes ha sido, por ejemplo, la fenomenología. Lo que esta comprensión de la filosofía sobre sí misma ha ganado sirve, igualmente, para examinar el pasado y obtener claridad sobre la unidad del principio que se indaga y de la historicidad de esa investigación. Semejante claridad se ha explicitado ya en repetidas ocasiones y puede ser todavía explorada. Cabe mencionar que, en apariencia, algunas posturas de la fenomenología se oponen a los supuestos básicos del idealismo, ya que la fenomenología busca la condición de posibilidad originaria de esas investigaciones categoriales que procuran "apresar" lo absoluto. No obstante, un fenomenólogo, Eduardo Nicol, hizo la siguiente observación sobre las ideas: "El saber de las cosas es indispensable para coexistir con ellas. El hombre es el único ser que requiere ideas para existir. Todo lo que existe coexiste [...]"

${ }^{39}$ Aristóteles, Metafísica, I, 9, 992a 24-25. El subrayado es mío.

${ }^{40}$ Ibid., I, 9, 992a 30-31.

${ }^{41}$ Ibid., I, 3, 984a 18-19.

42 Ibid., I, 3, 984b 10.

${ }^{43}$ E. Nicol, La primera teoría de la praxis. México, UNAM, Instituto de Investigaciones Filosóficas, 2007, \& 6, p. 67. 
En la tarea filosófica -que se repite una y otra vez- las distintas tomas de postura no implican la negación de otras concepciones. La fundamentación y la reflexión filosóficas no pueden ser particulares ni excluyentes. Como investigación de sí misma la filosofía fundamenta el todo y lo hace en todo sentido. En última instancia el reconocimiento de lo ya conocido no es una especialización, sino la posibilidad de toda reflexión. Esta posibilidad es la del integramiento. Con este concepto quiero referirme a un movimiento que complementa en un proceso continuo aquello que por sí mismo ya es completo. La reflexión común, gracias a las ideas, cohesiona la verdad en la historia, acrecienta el pensamiento sobre lo mismo y, en esa medida, se denomina filosofía. 